\title{
O Brasil da Economia Globalizada
}

\section{Resumo}

A globalização da economia, abrangendo a internacionalização da produção, o incremento do comércio e a absorção de tecnologia, é um processo que tem gerado discussões no âmbito acadêmico e empresarial, além de implicar novos desafios para os Estados Nacionais.

O movimento de internacionalização, impulsionado pela crescente desregulamentação das economias, a sofisticação dos mercados financeiros e os novos recursos das telecomunicações e da informática, criou o fator da intangibilidade da riqueza, fazendo com que os instrumentos tradicionais da política econômica (assim como o que ocorre com as teorias) se tornem insuficientes para influenciar significativamente a dinâmica do processo.

A reestruturação produtiva decorrente implica profundas transformações tanto nos países desenvolvidos quanto nos em desenvolvimento.

O Brasil, nesse contexto, convive simultaneamente com o impacto das transformações de âmbito internacional e o processo de estabilização da economia. Ambos afetam significativamente o desempenho econômico e o complexo produtivo, implicando novos desafios para a política econômica e a atuação das empresas.

\section{Abstract \\ The economy globalization, including the pro- duction internalization, the Commerce increment and the technology absorption, is a process which has caused discussion inside academic or occupational settings in addition to bring out new challenges for National States.}

The internationalization movement, stimulated by the economies new regulamentation, the financial market sophistication and the new telecommunication and information resources, has created the richness intangibility (such as it occurs with the theories) becoming insufficient for influencing significantly the process dynamic.

The decors productive new structuration to bring out deep transformations for developed countries as well those in developing process.

Brazil, in this context, lives together with the impact of international transformations simultaneously with the economic stabilization process. Both of them affect the economic performance and the productive complex significantly, bringing out new challenges for the economic policies and organizations actuating.

objetivo deste artigo é analisar alguns aspectos relativos à inserção brasileira na economia globalizada. Na primeira parte, subdividida em três seções, traça-se um quadro geral das grandes transformações em curso na economia mundial, processo esse que vem sendo genericamente chamado de globalização, assim como seus impactos na questão da reestruturação produtiva e o emprego. Adicionalmente, analisa-se o papel do Estado e das políticas econômicas, mostrando que, apesar do discurso liberal, grande parte dos países desenvolvidos continuam com uma participação expressiva estatal na economia e adotam políticas econômicas defensivas de seus mercados domésticos.

Na segunda parte, avalia-se a situação do Brasil, tendo em vista o cenário apresentado e os

* Antônio Corrêa de Lacerda, economista, mestre em Economia Política e professor do Departamento de Economia da FEA/PUC-SP, é presidente do Conselho Federal de Economia, Vice-presidente da Sobeet - Sociedade Brasileira de Estudos de Empresas Transnacionais e Globalização e autor do livro "O Impacto da Globalização na Economia Brasileira" (Editora Contexto, 1998), co-autor de "Planejamento no Brasil II" (Perspectiva, 1999) e "Economia Brasileira" (Saraiva, 1999) e organizador de "(Des) emprego e Globalização: Avaliação e Perspectivas” (Educ, 1998). E mail lacerda@cofecon.org.br. 
riscos e oportunidades envolvidos. A introdução do Plano Real e a valorização cambial provocaram a ampliação do déficit externo da economia brasileira, em grande parte impulsionado pelo crescimento dos gastos com importações, fretes e turismo, além dos juros sobre a dívida externa. $O$ aumento da dependência externa criou a armadilha dos juros altos, o que limitou o crescimento econômico, com impactos diretos na geração de valor agregado local e no emprego.

Mais recentemente, a mudança da política cambial permitiu uma melhora nas contas externas, livrando a economia da rigidez da política de juros altos, o que sinaliza aspectos positivos para a viabilização do crescimento econômico. No entanto, diante da ausência de um projeto mais claro de inserção internacional e de uma política de desenvolvimento, o Brasil pode perder a oportunidade de posicionar-se melhor em um cenário internacional altamente competitivo e disputado.

\section{Os novos desafios impostos pela globalização}

\subsection{A dinâmica da globalização}

A reflexão sobre os problemas advindos dessa fase do capitalismo globalizado tem trazido uma série de situações novas. De fato, a globalização da economia, abrangendo a internacionalização da produção, o incremento do comércio e a absorção de tecnologia, é um processo que tem gerado discussões no âmbito acadêmico e empresarial, além de implicar novos desafios para os Estados Nacionais, as empresas e os profissionais envolvidos.

O movimento de internacionalização, impulsionado pela crescente desregulamentação das economias, a sofisticação dos mercados financeiros e os novos recursos da telemática, criou o fator da intangibilidade da riqueza, fazendo com que os instrumentos tradicionais da política econômica (assim como o que ocorre com as teorias) se tornassem insuficientes para influenciar, significativamente, a dinâmica do processo ${ }^{1}$.

A reestruturação produtiva decorrente implica profundas transformações tanto nos países desenvolvidos quanto nos em desenvolvimento. A indústria tem o seu perfil alterado, com a crescente participação dos investimentos diretos estrangeiros, impulsionados em grande parte pelas fusões e aquisições, a privatização e o aumento do coeficiente de comércio externo no produto. $\mathrm{O}$ setor de serviços ganha nova dimensão, tanto pelo peso crescente na pauta de exportações dos países, quanto ao seu papel nas novas formas de geração de riqueza.

O Brasil, nesse contexto, convive, simultaneamente, com o impacto das transformações de âmbito internacional e o processo de estabilização da economia. Ambos afetam significativamente o desempenho econômico e o complexo produtivo, implicando novos desafios para a política econômica e a atuação das empresas.

O processo de internacionalização da produção, que avançou substancialmente a partir dos anos oitenta, tem provocado transformações nos planos tecnológico, organizacional e financeiro, intensificando a concorrência em escala mundial.

Não existe consenso a respeito do conceito de globalização. Há autores que o associam ao "grau, extensão, natureza e padrão da concorrência à escala mundial”. No entanto, se não há um consenso a respeito do conceito de globalização, não há dúvida de que esse é um fenômeno complexo que assume características distintas nas diferentes esferas das relações econômicas internacionais- produtiva-real, monetária-financeira, comercial e tecnológica.

Não obstante, parecem haver dois elementos comuns à dinâmica do sistema econômico mundial, independentemente da esfera, que são a aceleração da internacionalização e o acirramento da competição. A globalização é um con-

\footnotetext{
${ }^{1}$ Ver Lacerda, A.C. O Impacto da Globalização na Economia Brasileira. São Paulo, Contexto
} 
ceito novo e útil, à medida que envolve a sincronia desses dois elementos.

Do ponto de vista comercial, a globalização refere-se à expansão dos fluxos de comércio, num contexto de acirramento da concorrência em âmbito internacional, tornando a competitividade fator prioritário para o delineamento das políticas econômicas nacionais.

Do ponto de vista financeiro, a globalização está definida pela espetacular expansão dos fluxos financeiros internacionais. A tendencial desregulamentação financeira observada na maioria dos países, o avanço da internacionalização da produção de serviços financeiros ( como a colocação de títulos no mercado internacional e derivativos) e a liberalização cambial facilitaram a expansão das relações financeiras internacionais.

Na esfera produtiva, a globalização está ligada ao incremento dos fluxos de investimentos estrangeiros diretos, às estratégias da empresas transnacionais e ao processo de reestruturação empresarial, para fazer frente a este mercado cada vez mais competitivo.

Conforme o World Investment Report, de 1998, da UNCTAD (Conferência das Nações Unidas sobre Comércio e Desenvolvimento), a expansão do investimento direto estrangeiro tem se dado em proporção maior que o desempenho do crescimento econômico dos países e das exportações.

O volume total de investimentos diretos estrangeiros em 1998 atingiu US\$ 649 bilhões. Grande parte destes investimentos foram realizados nas próprias economias desenvolvidas; que absorvem cerca de dois terços do total. Mas os países em desenvolvimento vêm atraindo parcelas crescentes destes investimentos e têm absorvido um terço do total nos últimos anos.

Um aspecto importante, ligado ao crescente fluxo de recursos em nível internacional, é a aceleração do progresso tecnológico, implicando uma corrida competitiva internacional exigindo montantes extraordinários de investimentos em pesquisa e desenvolvimento.

A difusão de novas tecnologias em escala global se dá de forma tão rápida e generalizada, que gerou um novo paradigma tecnológico e gerencial. Essa corrida competitiva, envolvendo Estados Nacionais e empresas, tem sido caracterizada como a Terceira Revolução Industrial.

Todas essas esferas, comercial, financeira, produtiva e tecnológica interagem entre si. A globalização é um processo que atinge, simultaneamente, a todas essas esferas nas relações econômicas internacionais: a aceleração da internacionalização dos fluxos de bens, serviços e fatores, e o acirramento da concorrência em escala mundial

O lado financeiro desse processo está mais recentemente sendo evidenciado pela propagação da crise dos países asiáticos e da Rússia. Com a interligação dos mercados, propiciada pelos recursos da telemática, as transações e as informações ocorrem em tempo real, aumentando a volatilidade dos capitais. Diante de tanta agilidade, a melhor defesa é prender-se mais ao capital produtivo, do que criar dependência do capital especulativo, sem vínculo com a produção.

Da mesma forma, apesar da crescente dificuldade de fazê-lo, a correta combinação de políticas públicas, no sentido de fomentar a geração de poupança interna, aumentar o valor agregado local e a expansão das exportações, é a alternativa em um cenário cada vez mais turbulento. Aliás, a despeito do discurso liberal, essa estratégia não é nada diferente do que tem praticado a maioria dos países que tem sido bem-sucedidos economicamente, não raro, com elevadas doses de protecionismo.

\subsection{Globalização e Impactos no Emprego}

A questão do desemprego estrutural, ou seja, aquele decorrente do processo de reestruturação das economias, no contexto da globalização, surge como um dos principais problemas para os países industrializados. Há, segundo a UNCTAD, no mundo desenvolvido, um montante de 34 milhões de desempregados ${ }^{2}$.

Embora o comportamento do emprego nos 
países capitalistas avançados se mostre oscilante ao longo dos anos, observa-se uma tendência de aumento dessas taxas, desde a segunda metade da década de 1960. A significância das tendências e o nível das flutuações variam de país para país, tornando-se mais evidente nos países da Europa Ocidental, do que nos Estados Unidos e Japão.

A taxa média de desemprego nos países avançados (OECD), que era de 3,2\% no período 1960-1973, aumentou para 5,1\% no período 1974-1979 e, para 7,3\%, no período 1980-1984, denotando um claro processo de aumento (embora com taxas diferentes) em todos os países ${ }^{3}$.

$\mathrm{O}$ aumento do desemprego tem se dado muito mais intensamente no setor industrial, que perde participação relativa, enquanto gerador de emprego no âmbito dos países industrializados. A participação do setor industrial no emprego total dos países industrializados, que era de 37\% em meados dos anos 60 , caiu gradativamente, já que no início dos anos 90 era de 26\%. No mesmo período, aumentou a participação relativa do setor de serviços, que cresceu de $41 \%$ para $67 \%$.

Observou-se uma queda representativa do número absoluto de empregos no setor industrial. Houve uma perda de 8,3 milhões de postos de trabalho no setor industrial dos países avançados, que se mostrou mais intensa no setor têxtil e de vestuário (3,5 milhões), e metais ferrosos (1,7 milhão ). Em todos os casos, há um aumento dos desempregados de longo prazo, ou seja, aqueles que ficam fora do mercado de trabalho por um período superior a um ano.

A análise das tendências de geração de emprego nos países avançados revela que o problema tende a agravar. Cenários de projeção constatam que, para que os países conseguissem diminuir o desemprego, haveria necessidade de um crescimento econômico muito mais expressivo do que o que se espera para os próximos anos.

Assim, na questão do emprego, além dos aspectos conjunturais envolvidos, há uma mudança estrutural importante, o que aumenta o desafio da geração de lugares de trabalho e renda, especialmente nos países em desenvolvimento, em que o Estado dificilmente tem as condições para a geração e manutenção de políticas compensatórias.

\subsection{Política Econômica: entre o Discurso e a Prática}

A globalização tem gerado uma série de mitos sobre a inviabilização de políticas econômicas ativas e a atuação dos Estados Nacionais. No entanto, não é o que se observa na prática. Embora a maioria dos países adotem um discurso liberalizante, a prática é intervencionista e protecionista.

De acordo com dados da OCDE, elencados na Tabela 1, considerando-se o conjunto do G-7, nos sete países mais ricos do mundo, que respondem por cerca de $80 \%$ do PIB de todos os membros da OCDE, o gasto público em proporção ao PIB cresceu de 36,3\% no período 1978-1982 para $39,4 \%$, entre 1991-1995, o que denota que, apesar do discurso de redução do Estado, o que se tem observado na prática é um aumento da sua participação.

\footnotetext{
${ }^{2}$ Número equivalente ao desemprego aberto nos países membros da OECD, em 1974. Ver UNCTAD, Trade and Development Report, 1995, p. IV.

3 Idem, ibidem.
} 


\section{Tabela 1}

\section{SETOR PÚBLICO ${ }^{(1)}$ NOS PAÍSES DO G-7}

\begin{tabular}{|c|c|c|c|c|c|c|c|}
\hline Paises & Período & $\begin{array}{c}\text { Gasto } \\
\text { Público }^{(2)}\end{array}$ & $\begin{array}{c}\text { Carga } \\
\text { tributária }\end{array}$ & $\begin{array}{l}\text { Juros } \\
\text { líquidos }\end{array}$ & $\begin{array}{l}\text { Déficit } \\
\text { público }\end{array}$ & $\begin{array}{c}\text { Dívida } \\
\text { pública bruta }\end{array}$ & $\begin{array}{c}\text { Dívida pública } \\
\text { líquida }{ }^{(4)}\end{array}$ \\
\hline ESTADO UNIDOS & $\begin{array}{l}1978 / 82 \\
1991 / 95\end{array}$ & $\begin{array}{l}31,2 \\
33,6\end{array}$ & $\begin{array}{l}30,1 \\
30,5\end{array}$ & $\begin{array}{l}1,3 \\
2,1\end{array}$ & $\begin{array}{l}1,1 \\
3,1\end{array}$ & $\begin{array}{l}37,9 \\
62,6\end{array}$ & $\begin{array}{l}22,3 \\
47,7\end{array}$ \\
\hline JAPÃO & $\begin{array}{l}1978 / 82 \\
1991 / 95\end{array}$ & $\begin{array}{l}31,8 \\
33,2\end{array}$ & $\begin{array}{l}27,4 \\
32,7\end{array}$ & $\begin{array}{l}1,0 \\
0,3\end{array}$ & $\begin{array}{l}4,4 \\
0,4\end{array}$ & $\begin{array}{l}50,7 \\
69,5\end{array}$ & $\begin{array}{r}16,4 \\
6,1\end{array}$ \\
\hline ALEMANHA & $\begin{array}{l}1978 / 82^{(5)} \\
1991 / 95\end{array}$ & $\begin{array}{l}48,0 \\
48,9\end{array}$ & $\begin{array}{l}45,0 \\
45,7\end{array}$ & $\begin{array}{l}1,4 \\
2,6\end{array}$ & $\begin{array}{l}3,0 \\
3,1\end{array}$ & $\begin{array}{l}34,0 \\
51,1\end{array}$ & $\begin{array}{l}13,1 \\
33,5\end{array}$ \\
\hline FRANÇA & $\begin{array}{l}1978 / 82 \\
1991 / 95\end{array}$ & $\begin{array}{l}46,9 \\
53,0\end{array}$ & $\begin{array}{l}45,4 \\
48,6\end{array}$ & $\begin{array}{l}0,9 \\
2,9\end{array}$ & $\begin{array}{l}1,5 \\
4,4\end{array}$ & $\begin{array}{l}31,5 \\
51,1\end{array}$ & $\begin{array}{r}0,1 \\
25,3\end{array}$ \\
\hline ITÁLIA & $\begin{array}{l}1978 / 82 \\
1991 / 95\end{array}$ & $\begin{array}{l}44,0 \\
54,1\end{array}$ & $\begin{array}{l}33,7 \\
45,0\end{array}$ & $\begin{array}{l}4,8 \\
9,9\end{array}$ & $\begin{array}{r}10,4 \\
9,1\end{array}$ & $\begin{array}{r}61,3 \\
116,8\end{array}$ & $\begin{array}{r}56,8 \\
101,1\end{array}$ \\
\hline REINO UNIDO & $\begin{array}{l}1978 / 82 \\
1991 / 95\end{array}$ & $\begin{array}{l}42,8 \\
42,7\end{array}$ & $\begin{array}{l}39,6 \\
36,9\end{array}$ & $\begin{array}{l}3,0 \\
2,4\end{array}$ & $\begin{array}{l}3,2 \\
5,8\end{array}$ & $\begin{array}{l}54,9 \\
51,8\end{array}$ & $\begin{array}{l}39,9 \\
31,7\end{array}$ \\
\hline CANADÁ & $\begin{array}{l}1978 / 82 \\
1991 / 95\end{array}$ & $\begin{array}{l}39,9 \\
48,5\end{array}$ & $\begin{array}{l}36,8 \\
42,4\end{array}$ & $\begin{array}{l}2,1 \\
5,2\end{array}$ & $\begin{array}{l}3,1 \\
6,1\end{array}$ & $\begin{array}{l}45,7 \\
91,6\end{array}$ & $\begin{array}{l}13,4 \\
61,1\end{array}$ \\
\hline G-7 ${ }^{(6)}$ & $\begin{array}{l}1978 / 82 \\
1991 / 95\end{array}$ & $\begin{array}{l}36,3 \\
39,4\end{array}$ & $\begin{array}{l}33,5 \\
35,9\end{array}$ & $\begin{array}{l}1,6 \\
2,6\end{array}$ & $\begin{array}{l}2,9 \\
3,5\end{array}$ & $\begin{array}{l}42,6 \\
66,2\end{array}$ & $\begin{array}{l}22,0 \\
40,4\end{array}$ \\
\hline
\end{tabular}

(1) Inclui governos centrais, estaduais e locais.

(2) Despesas correntes mais despesas líquidas de capital.

(3) Receitas correntes. Exclui receitas de capital.

(4) Dívida bruta menos ativos financeiros.

(5) Alemanha Ocidental.

(6) Médias ponderadas com base no PIB dos sete países. Pesos utilizados: Estados Unidos - 0,4525; Japão - 0,1812; Alemanha - 0,1038; França - 0,0793; Itália - 0,0743; Reino Unido - 0,0689; Canadá - 0,0400 Fonte: Organisation for Economic Co-operation and Development. OECD Economic Outlook, Dec. 1996 and Jun. 1995.

Também no que se refere às políticas econômicas praticadas, observa-se uma clara dicotomia entre o discurso e a prática. Não há dúvida que as transformações em curso representam novos desafios, tanto do ponto de vista macro, quanto microeconômico. Do ponto de vista macroeconômico, diminuem a autonomia dos Estados Nacionais no delineamento da política econômica. Entetanto, exigem o fortalecimento do aspecto regulatório, no que se refere ao comércio, aos investimentos, à propriedade intelectual. Também parece um fato que a maioria dos países bem-sucedidos no desenvolvimento não tem aberto mão de formular e implementar um conjunto de políticas públicas, a despeito da dificuldade em fazê-lo ${ }^{4}$.

Já no âmbito microeconômico, a internacionalização da produção, aliada ao novo paradigma tecnológico pós-fordista-taylorista, representa um enorme choque de competitividade nas empresas, que então se vêem às voltas com novos concorrentes nacionais e internacionais, um processo crescente de fusões e aquisições, que as levou ao processo de novas formas de produção.

\footnotetext{
${ }^{4}$ Países europeus, em geral, também têm adotado essa estratégia
} 
O cuidado que os EUA têm tido na questão da abertura da sua economia, combate à concorrência predatória, dumping e também na promoção de exportações, é algo que ilustra bem o peso desses temas no cenário internacional. $\mathrm{O}$ governo americano investirá este ano US \$ 2,3 bilhões na promoção e financiamento da venda de bens e serviços de empresas americanas no exterior, para protegê-las contra o que considera práticas desleais de comércio, justificar as barreiras tarifárias e não tarifárias praticadas internamente e na negociação de acordos internacionais que propiciem benefícios para a economia do país.

Cerca de 20.000 funcionários federais americanos são comprometidos com as diversas operações nessa área, que envolve mais de 40 agências oficiais no país e cerca de 130 representações espalhadas por 75 mercados potenciais. A avaliação do governo americano, constante no relatório "Estratégia Nacional de Exportações" enviado ao seu Congresso, é de que cerca de um terço do crescimento da economia desde 1993 e 1,5 milhão dos 8 milhões de empregos gerados no período foram resultantes diretamente das exportações, cujo crescimento acumulado foi de 35\%, no período 1993-1996 ${ }^{5}$.

$\mathrm{Na}$ Europa, há uma longa tradição de integração regional, a partir das bases do Mercado Comum Europeu e os temas referentes à política externa são exaustivamente debatidos há décadas. A Comissão Européia decidiu recentemente restabelecer um preço mínimo para os chips importados. A iniciativa visa proteger o produtor local da concorrência predatória externa, especialmente a asiática, que já detém mais de $60 \%$ do mercado europeu de US $\$ 5,7$ bilhões. $\mathrm{O}$ assunto tem sido polêmico, já que atinge diretamente os produtores locais, os consumidores e os atuais fornecedores, com destaque para os japoneses ${ }^{6}$.

As experiências dos principais emergentes, em especial os asiáticos, também têm se dado com ênfase em políticas ativas de comércio exterior e de desenvolvimento. Nesse contexto, é fundamental que a política econômica adote posturas ativas em contraposição às reativas, uma vez que a intangibilidade crescente da riqueza exige a sofisticação e renovação dos instrumentos tradicionais que perderam eficácia no novo paradigma.

A atitude protecionista por parte dos países centrais ficou clara na recente reunião de Seattle, preparatória para as discussões da chamada Rodada do Milênio, no âmbito da OMC (Organização Mundial do Comércio). Apesar dos esforços empreendidos pelo Brasil e demais países em desenvolvimento, os países ricos não sinalizaram nenhum recuo na sua política protecionista em relação à agricultura (no caso da Europa, que pratica enormes subsídios) e na política anti-dumping (no caso norte-americano, que se transforma em um protecionismo disfarçado) ${ }^{7}$.

\section{Os impactos do cenário externo na economia brasileira}

\subsection{Plano Real: Adaptação às mudanças e vul- nerabilidade}

Os riscos presentes nessa fase do capitalismo contemporâneo em que os novos paradigmas de produção, mas também e principalmente da hegemonia do capital financeiro, dão as cartas do jogo internacional, já foram há muito alertados por vários analistas. Até mesmo o presidente do Federal Reserve, Sr. Alan Greenspan, já se referira à "exuberância irracional" dos mercados.

A turbulência em algumas economias tende a afetar, de uma forma geral, todas as demais, com predominância daquelas em que os "fundamentos” estejam fragilizados. É fruto da globalização, que propiciou maior velocidade e magnitude das

\footnotetext{
5 Conforme "O Estado de São Paulo", 01.10.96, p. b-3.

Idem, ibidem

${ }^{7}$ Ver Gazeta Mercantil Latino Americana, "Muito barulho, nenhum resultado", p.32, de 13 a 19 de dezembro de 1999
} 
transações financeiras e do fluxo de informações. Os mercados funcionam on line vinte e quatro horas por dia e isso representa um novo desafio para as políticas e os agentes econômicos.

Assim, é inevitável que uma crise que afete com maior ou menor intensidade toda a economia mundial também tenha seus reflexos no Brasil. Daí a afirmar-se que a crise atual da economia brasileira, que combina baixo crescimento, juros elevados, inadimplência etc. seja fruto exclusivo da instabilidade externa, é exagero, ou fuga dos nossos reais problemas.

$\mathrm{Na}$ verdade, o Brasil optou por uma política econômica, a partir de 1994, que privilegiou um bem sucedido programa de estabilização ancorado na valorização cambial e na prática de juros elevados. A baixa da inflação permitiu a expansão do consumo nos dois primeiros anos do programa, que teve que ser abortado, inicialmente em 1995, com medidas de restrição de crédito para reduzir a atividade e evitar um impacto maior no déficit da balança comercial. Também em 1995, o governo reconheceu a sobrevalorização cambial e adotou, corretamente, um processo de desvalorização gradual da taxa de câmbio.

No entanto, isso não impediu a expansão crescente do déficit das contas correntes do balanço de pagamentos, que partiu de cerca de US\$ 1,6 bilhão em 1994, para atingir US\$33,4 em 1998. O que por si só não seria um problema grave, se a poupança externa representada pelo financiamento sadio do déficit corrente alavancasse os investimentos físicos, e não o excesso de gastos governamentais por conta do financiamento da dívida pública.

Em outubro de 1997, diante do agravamento da situação de alguns dos "tigre asiáticos", e a persistência dos nossos déficits-gêmeos, das contas correntes do Balanço de Pagamentos, que chegara a 4,2\% do PIB (Produto Interno Bruto) e do déficit público a $5 \%$ do PIB, o governo brasileiro adotou um pacote fiscal, combinando aumento de receitas e promessas de corte de gastos, visando um ajuste de US $\$ 20$ bilhões, além de praticamente duplicar a taxa básica de juros para $43 \%$ ao ano.

O efeito dessas medidas restringiu a quase zero o crescimento econômico de 1998, provocando o agravamento da inadimplência e a elevação da taxa de desemprego aberto apurada pelo IBGE (Instituto Brasileiro de Geografia e Estatística), que subiu dos então 5,5\% da PEA (População Economicamente Ativa) para mais de $8 \%$. Assim, os desdobramentos da crise Russa, que complicaram o quadro internacional, vieram significar uma dificuldade adicional para o Brasil, que já se encontrava numa situação de vulnerabilidade.

A estagnação da economia brasileira e o agravamento do passivo externo mostrava a insustentabilidade da política cambial que valorizava nossa moeda. Essa prática exigia juros reais extremamente elevados para atrair capitais externos, o que gerava um custo elevado de financiamento da dívida pública e inviabilizava o ajuste fiscal, apesar da elevação da carga tributária.

governo resistiu em mudar sua política econômica, apesar das evidências de sua necessidade, também por razões políticas, em função da realização de eleições em novembro de 1998, o que adiou perigosamente a desvalorização cambial, que se mostrava inevitável. Em meados de janeiro de 1999, coincidindo com a saída de Gustavo Franco da presidência do Banco Central, o governo muda a sua política cambial, adotando a flexibilização do câmbio. Seguem-se meses de turbulência nos mercados financeiros e instabilidade do nível de atividades.

\subsection{9: o efeito da desvalorização cambial}

As condições para a retomada do crescimento econômico em bases sustentadas, após dois anos de estagnação do produto e duas décadas de estagnação do produto per capita, têm suscitado intenso debate. Isso por si só traz um aspecto positivo, à medida que começa a esboçar uma discussão mais ampla sobre as condições estruturais da economia brasileira, algo que extrapola a 
abordagem essencialmente conjuntural, da qual nos tornamos reféns, com a política econômica em prática no primeiro mandato do atual governo.

A desvalorização cambial, a partir de janeiro de 1999, alterou positivamente a agenda e a expectativa sobre o comportamento do nível de atividade econômica. Há evidente melhora no desempenho do valor agregado local, seja através da substituição de importações ou ampliação quantitativa das exportações. $\mathrm{O}$ comportamento dos preços internacionais, que determinaram uma deterioração das relações de troca desfavorável ao Brasil, tem impedido que este resultado reflita mais intensamente no desempenho da balança comercial, como veremos mais adiante.

A nova substituição de importações se dá, em um primeiro momento, em setores de tecnologia tradicional e que foram fortemente afetados pela valorização cambial dos últimos anos. Nesse caso se encaixam, entre outros, bens de consumo em geral, onde já existe uma base instalada, um relativo domínio da tecnologia e economia de escala para atendimento do mercado interno, além do externo.

Quanto às exportações, a questão é mais complexa. Em primeiro lugar, o aumento da disposição de oferta por parte dos produtores brasileiros não significa, automática e necessariamente, a demanda dos importadores no mercado internacional. Além disso, o baixo crescimento do comércio mundial, a queda dos preços dos bens transacionáveis, especialmente commodities agrícolas, e o efeito das desvalorizações dos asiáticos que têm provocado quedas de preços de mercado, implica que nem sempre maiores volumes de mercadorias exportadas signifiquem maior receita.

Uma análise pormenorizada dos dados do desempenho da balança comercial de 1999, especialmente na área agrícola, revela-nos que, para um aumento de 7,6\% no volume em toneladas exportado, a receita em dólares caiu quase 10\%. Ou seja, na balança agrícola, houve uma perda de receita de cerca de 18\%. Como no lado das importações houve um aumento de preços do petróleo, é significativa a deterioração dos termos de troca, o que foi determinante, para que não gerasse um superávit na balança comercial.

Os dados mais recentes apontam para uma tendência de crescimento do volume global exportado. A Funcex (Fundação Centro de Estudos do Comércio Exterior) analisou o desempenho e detecta um crescimento no volume (quantum) exportado. Tudo leva a crer que o desempenho continuará evoluindo de forma significativa, o que nos permite vislumbrar para 2000 o retorno do superávit comercial, tendo em vista não só as condições externas, mas o cenário internacional que aponta a recuperação da economia asiática e uma reversão da situação de preços atualmente desfavorável à pauta brasileira de exportação.

É uma melhora significativa, mas insuficiente para minimizar a restrição externa. Nesse sentido, é preciso destacar que nos dois casos, tanto na substituição de importações quanto no caso das exportações, a desvalorização cambial é uma condição necessária, mas não suficiente para garantir o rompimento da restrição externa decorrente dos erros da política econômica dos últimos anos, especialmente a valorização do câmbio, a ausência de uma política de desenvolvimento (entendida como a articulação da política industrial, comercial, ciência e tecnologia, etc), os elevados juros, o que determinou um processo de inserção passiva do Brasil no cenário internacional.

Além da estagnação da economia e o conseqüente aumento da quebra de empresas, inadimplência elevada e crescimento do desemprego, um dos principais efeitos da política econômica pós-real está no aumento significativo do déficit em transações correntes, que cresceu de um resultado praticamente de equilíbrio quando da introdução da nova moeda, em 1994 e, rapidamente, evoluiu para um nível superior a $4 \%$ do PIB, resultado que persiste atualmente.

E aí temos não só o efeito do déficit na balança comercial, como também e, principalmente, a 
dos serviços, com destaque para os juros, a remessa de lucros e dividendos das empresas transacionais, a conta de viagens internacionais e os gastos com fretes e seguros. Destes itens, somente o último, tendo em vista sua elasticidade relativamente à desvalorização, tem condições de reverter-se, como de fato já vem ocorrendo. A redução do déficit em transações correntes desse ano, portanto, é fruto direto da desvalorização cambial, da diminuição do déficit comercial e das despesas de fretes e seguro; além dos gastos de viagens internacionais.

Mas, a questão central é que, em condições internas e externas diferentes, retomamos, nesse final da década de noventa, a restrição externa vivida pelo Brasil no início dos anos oitenta, em que o comportamento "stop and go" da economia brasileira foi determinante para o resultado da década perdida. $\mathrm{O}$ avanço do passivo externo líquido, que cresceu de US\$ 168 bilhões em 1993, para US\$ 324 em 1998, justamente no momento em que os efeitos das crises asiática e russa tornavam mais seletivo o financiamento aos países em desenvolvimento.

Embora em 1999 tenha ocorrido uma diminuição substantiva do déficit em transações correntes medido em números absolutos, essa diminuição será quase imperceptível em termos relativos ( em porcentagem do PIB- Produto interno Bruto), já que expresso em dólares, o valor do PIB diminuirá substancialmente pelo efeito da desvalorização cambial : (de cerca de US $\$ 800$ bilhões, em 1998, para menos de US\$ 600 bilhões, em 1999).

A questão é que há um desequilíbrio estrutural da balança de serviços decorrente principalmente da conta de juros e remessas de lucros e dividendos que, para ser compensada, depende fundamentalmente de um superávite na balança comercial. Ou seja, para eliminar a restrição externa ao crescimento, é fundamental que as exportações cresçam acima das importações e do nível de atividades.

Nesse sentido, as exportações são imprescindíveis para a economia brasileira, não só pelo efeito na ampliação da produção, renda e emprego, mas também, principalmente, para diminuir a nossa vulnerabilidade externa representada pelo resistente déficit em transações correntes do balanço de pagamentos, especialmente pela rigidez na conta de serviços. Assim, não se trata da dicotomia, ou da escolha entre mercado interno e externo, mas uma situação em que também a evolução do nível de atividades do mercado interno depende do desempenho exportador, uma vez que a restrição externa impede o crescimento sustentado da economia, como de fato vem ocorrendo desde o início da década de oitenta.

Quanto à condução da política econômica e suas opções, a experiência destes últimos meses nos trouxe algumas lições importantes. Apesar de tardia e realizada de maneira atabalhoada, a desvalorização cambial trouxe uma nova dinâmica para a economia brasileira e a oportunidade de uma virada na política econômica, de forma a compatibilizar estabilização de preços com uma política de desenvolvimento.

Isso, no entanto, não vai ocorrer, naturalmente, de uma forma automática. É algo que requer perícia no manejo dos instrumentos e comprometimento do setor privado. É preciso adotar um conjunto de políticas ativas, voltadas para as áreas agrícola, industrial e de serviços, agregando elementos da ciência e tecnologia e conduzindo corretamente a política comercial, especialmente nos grandes fóruns internacionais. Adicionalmente, é preciso fomentar a melhora do conteúdo tecnológico dos produtos brasileiros de exportação e ampliar a promoção comercial nos mercados dinâmicos onde o Brasil possua condições de competitividade. 